\title{
Impact of Collaborative Processes on the Success of Construction Projects in Nigeria
}

\author{
Dorcas Titilayo Moyanga ${ }^{*}$, Charles Preye Adeoye \\ Department of Quantity Surveying, Federal University of Technology, Akure, Nigeria \\ Email address: \\ dorky_2001@yahoo.com (D. T. Moyanga),dtmoyanga@futa.edu.ng (D. T. Moyanga), adeoyechrist@gmail.com (C. P. Adeoye) \\ ${ }^{*}$ Corresponding author
}

To cite this article:

Dorcas Titilayo Moyanga, Charles Preye Adeoye. Impact of Collaborative Processes on the Success of Construction Projects in Nigeria.

American Journal of Construction and Building Materials. Vol. 5, No. 1, 2021, pp. 10-14. doi: 10.11648/j.ajcbm.20210501.12

Received: February 4, 2021; Accepted: February 20, 2021; Published: April 29, 2021

\begin{abstract}
Collaboration is essential to the success of construction projects and a defined collaborative process is one of the key elements of a successful relationship in construction. Although the consultant and contractor are key stakeholders in construction yet it is not being proven how their relationship affect projects in Nigeria's construction industry. Therefore, this study evaluates the effect of collaboration on the success of construction projects. Quantitative study was conducted and primary data were collected through structured questionnaire on collaborative processes, success factors of projects in relation to collaboration and the impact of consultant-contractor collaboration on project success. The data collected from 135 consulting and construction firms in Lagos, Nigeria was analyzed using frequency distribution, mean score, ANOVA and multiple regression. The finding of the study revealed that the consultants and contractors are involved in the collaboration processes though they are mostly involved clear roles and responsibility, information sharing, cooperation and coordination, improved communication and collaborative governance. Also, the finding revealed that efficient coordination and dedicated team are the collaborative factors that contribute more to project success. Conclusively, the finding depicts that effective and efficient collaboration between consultant and contractor significantly impact the success of construction projects with $\mathrm{R}^{2}$ as 0.7403. The implication of the study is that project actors should continually accept and practice all levels and processes of collaboration and so as achieve a successful project delivery and pave way for the implementation of digital collaboration in Nigeria's construction industry.
\end{abstract}

Keywords: Collaborative Process, Construction Project, Collaboration, Nigeria, Project Success

\section{Introduction}

In the construction industry, collaboration is crucial for the successful completion of construction projects within time and budget $[1,21]$. Collaboration is simply a relationship between two or more organizations to collectively address problems and deliver results. Although Collaboration is a concept that reflects the perspective through which a speaker/writer views it. Thus, irrespective of types; forms and characteristics, collaboration is described as a mutual agreement between two or more partners through communication and networking so as to solve a problem [22, 11]. Collaboration is built on commitment for mutual relationships, shared responsibility and goals which requires comprehensive planning and well defined communication channels. Collaboration is effective when it involves the exchange of information, sharing of resources, engaging all members for mutual benefit [19] and designing a rigorous process for success and positive change [34]. The collaborative process designed entails norms, mutuality, governance and administration among the partners.

The construction industry though referred to as the industry that contributes significantly to nation's economic development through the involvement of different people and organizations, is falling short in term of collaboration [23, 4]. The problem in achieving the desired outcomes of collaboration, may be due to premise that the clients are slightly satisfied with projects executed collaboratively [18]. Also, the construction industry involves construction projects that are built by project actors competing with each other. In recent years, the poor communication and transfer of information stemmed from the complex nature of the 
construction industry [24]. Similarly, the construction industry's lack in terms of collaboration has given rise to various negative outcomes, such as project delays, missing information, poor resource distribution, profit loss and even reworks that are having a strong negative impact on construction as whole [25]. This is supported by the argument that collaboration is still a relatively new approach to project delivery because its value is still being debated [27]. Nevertheless, introducing collaboration in the construction process encourages teamwork and stimulates better communication among project parties [1]. Furthermore, collaboration enhances successful project delivery, and establishes long-term relationships for future projects [27, 30]. Likewise, having a defined collaborative process is indispensable because it offers temporary governance structure for collaboration [19]. However, despite the importance and effects of collaboration as submitted by previous studies, the level of adoption and involvement of collaboration by project actor is still low [4]. This implied that larger percentage of people and organizations in the construction industry are not fully involved in all levels and processes of collaboration. Nevertheless, the consultant and contractor play crucial roles in the successful execution of construction projects and few studies are known to have explored the interrelationship of consultants and contractors in achieving project success in Nigeria's construction industry. Hence, there is a need to assess the effect of consultant-contractor collaboration on construction project success in Nigeria.

\section{Literature Review}

\subsection{Collaboration in Construction}

The construction industry is an important sector of the economy and involves variety of stakeholders or project participants. Based on this nature of construction industry, people and organizations cooperate or collaborate together to achieve desired project outcome. Collaboration, though subjective in nature, connotes a more durable and pervasive relationship. Collaboration is defined and seen by different research based on the way they view it. Collaboration is described as a process in which information and resources are shared by participants to jointly achieve a common goal [2]. Similarly, collaboration is defined as a process involving multiple people working together to accomplish tasks [31]. Also, collaboration is defined as the "mutual engagement of participants in a coordinated effort to solve a problem together" [22]. Collaboration is also viewed as identifying shared goals in which people worked together towards a common goal [32]. Collaboration is simply the shared effort as well as activity by a group of people who contribute to the efficiency of the whole project [27].

The levels of collaboration and their characteristics include networking, cooperating, connecting, merging, unifying, coordination, coalition [17]. It is crucial for the project team to be aware that the degree of cooperation within them increases with time [20]. That being said, it is believed that long term partnership is a better option when it comes to achieving the goals, objectives and sustainable advantages. In addition, collaborative process is essential for the parties in construction to achieve the expected result as they relate. Collaboration is a process involving shared norms and mutually beneficial interactions [35]. Elaborately, collaborative processes is categories under five dimensions and concepts, which include governance, administration and autonomy, the mutuality, trust and reciprocity dimension.

Mutuality is derived from the word mutual and simply means the exchange of individual interest with collective one The concept of mutuality is relevant to organizations desiring to work together to achieve a common goal. This implied that mutuality is germane component of collaborative process. Mutuality is acquiring resources from other organizations for their collective continuing functioning [9]. Mutuality is the way of achieving share benefits, respect, learning, interest in collaboration [6, 28]. Governance is described in several studies as collaborative governance and it is simply a process in which organizations with varying interest are empowered to solving problems together.

Governance is also described as shared power arrangements; information sharing, respect for others, negotiations to reach agreement [35]. Contrariwise, collaborative governance is also described by studies as the process of collaboration in which single organization (private) involving public entity (government) to accomplish public tasks [9]. Governance is the process of partnership involving public and private sectors to accomplish public tasks [14].

The process administration in collaboration entails basically the management of parties in a cooperative way. The concept of administration also implied the process of simulating and unifying collective interests. Collaborative administration is stressed as being essential for the successful management and coordination of relationships [12].

The concept of autonomy is described as parties or actors being able to collectively achieve outcome while working independently. Collaborative autonomy is having understanding about the general concept of how to tackle a problem and applying it to individual concept without discarding one's thinking [26]. Lastly, the process of building social and capital norms represents the moderating behavior of parties as expected. Summarily, collaborative process involves the concept of norms, mutuality, governance, administration and organizational autonomy. However, this current study included the concept of technology usage and communication as a result of the advancement in technology and innovation.

\subsection{Impact of Collaboration on Project Success}

Collaboration in projects has a different way of allocating risks than most other governance forms [15]. The success factors and benefits of project partnering in Nigerian construction industry is being examine and the study stated that the adoption of project partnering is increasingly been used as one of the innovative tools for effective quality 
changes on construction projects and overhaul the shortcomings of traditional approach to procurement system [7]. The essence of collaboration encompasses common goal, shared responsibility and joint completion at a project level. These characteristics are also the key factors of project success in construction projects [31]. Collaboration and communication is conceived as the key to achieving project objectives and goal. Success factors are variables that contribute to projects' success thereby increasing the chances of obtaining the desired outcomes [36]. The investigation within the field of construction management discovered that there existed the effect of collaboration in project on construction project performance [23]. The study stated that collaboration among project actors has been subjected too much attention in recent years within the field of construction management. Results from hierarchical regression analyses show a positive relationship was also found between collaboration and project performance. Collaboration is critical to successfully move project from estimating to the field and leads to time savings, cost savings and adds value to the client [21].

Efficient coordination, dedicated team, commitment to quality, partnership formation at design stage, commitment, flexibility to change, productive conflict resolution strategy and long term commitment are six significance success factors related to collaborative team culture [10]. A combination of factors determines the success or failure of a project and influencing these factors at the right time makes success more probable [33].

\section{Research Methodology}

This study adopted the quantitative research design and primary data was obtained through the survey method from registered constructing and consulting firms in Lagos State, Nigeria. The total number of these firms is two hundred and forty-nine (249) and the sample size of 135 was gotten with the use of Yamane formula at $10 \%$ margin of error (MOE). Well-structured questionnaires divided into 3 sections, were distributed to consulting and construction firms. Section 1 addressed questions on the background information of the respondents; section 2 addressed the collaborative processes while section 3 addressed the success factors in relation to collaboration. The questions were rated based on 5-point likert scale with 1 as very low and 5 as very high. The data collected was analysed using frequency distribution and percentage, mean item score (MIS), analysis of variance (ANOVA) and regression analysis.

In regression analysis, the independent variable (X) predicts the dependent variable (Y). Regression analysis was used to analyze the impact of collaboration processes between project actors on project success, with collaboration processes represents the independent variable while the collaborative success factors as the dependent variable.

\section{Results and Discussion}

Out of the one hundred and two (135) questionnaires distributed, 105 was retrieved and suitable for analysis. The questionnaire analyzed represented $78 \%$ healthy response rate. The result showed that $62 \%$ of the firms are into contracting businesses while $38 \%$ into consulting businesses in Lagos, Nigeria. Also, the respondents have an average of 6 years working experience. $39 \%$ of the respondents are quantity surveyors. $16 \%$ are architects, $13 \%$ are civil engineers, $11 \%$ are builders, $9 \%$ are structural engineers while $6 \%$ are electrical engineers and lastly $6 \%$ of the respondents are mechanical engineers in both consulting and contracting firms.

\subsection{Level of Involvement in Collaborative Process}

Table 1 showed the level of involvement of collaborative processes among project actors. The results revealed that consultants and contractors are involved in all the collaborative processes. In previous studies, process designed for collaboration involves norm, mutuality, governance and administration. However, in this current study, the collaborative process also includes communication and use of technologies. The finding revealed that clear roles and responsibility, information sharing, cooperation and coordination, improved communication and collaborative governance are collaborative processes that are mostly involved in by the contractor and consultant. This is in agreement with the findings which states that information sharing is important [29], and the findings which states that cooperation is an inter-organizational relationship process for solving problems in organizations [5].

Table 1. Level of Involvement in Collaborative Processes.

\begin{tabular}{lll}
\hline Collaborative Processes & Mean score & Rank \\
\hline Clear roles and responsibility & 3.75 & 1 \\
Information sharing & 3.75 & 2 \\
Cooperation and coordination & 3.71 & 3 \\
Improved communication & 3.68 & 4 \\
Collaborative governance & 3.65 & 5 \\
Interest unifying Process & 3.59 & 6 \\
Building mutual relationships & 3.52 & 7 \\
Joint decision making & 3.51 & 8 \\
Use of technologies e.g. BIM & 3.42 & 9 \\
Collaborative administration & 3.41 & 10 \\
Building social capital norms & 3.34 & 11 \\
\hline
\end{tabular}

Source: Author's field survey (2018)

Success factors of project based on effective collaboration was also examined. The results on Table 2 revealed that all the factors highlighted contributed to the success of project though, efficient coordination and dedicated team contributed more to project success are the success factors that contribute most to project success based on effective collaboration. The finding of this current study slightly support to this finding which assesses the importance of collaboration in construction and found out that encourage teamwork, improve cooperation, stimulated information sharing and improve quality are the factors that leads to successful collaboration [1]. 
Table 2. Success Factors of Project based on Effective Collaboration.

\begin{tabular}{lll}
\hline Success factors & Mean score & Ranking \\
\hline Efficient coordination & 4.44 & 1 \\
Dedicated team & 4.33 & 2 \\
Commitment to Quality & 4.19 & 3 \\
Partnership formation at design stage & 4.13 & 4 \\
Commitment to Win-Win Attitude & 4.12 & 5 \\
Flexibility to change & 4.03 & 6 \\
Productive Conflict Resolution Strategy & 3.95 & 7 \\
Long term commitment & 3.85 & 8 \\
\hline
\end{tabular}

\subsection{Impact of Collaborative Processes between Project Actors on Project Success}

The analysis of variance (ANOVA) was used to determine a relationship between collaborative process and project success. The result of ANOVA on Table 3 showed that the $\mathrm{P}$ value $=0.001398,<0.05$ indicates a significant relationship between collaborative processes and the success of construction projects in Nigeria.

Table 3. Relationship between Collaborative Processes and Project Success.

\begin{tabular}{lllllll}
\hline Model & & $\boldsymbol{d f}$ & $\boldsymbol{S S}$ & $\boldsymbol{M S}$ & $\boldsymbol{P}$ & 22.808 \\
\hline \multirow{3}{*}{1} & Regression & 1 & 26.064 & 26.064 & 0.001 \\
& Residual & 8 & 9.142 & 1.143 & \\
& Total & 9 & 35.206 & & \\
\hline
\end{tabular}

Note: $\mathrm{SS}=$ Sum of Square; $\mathrm{MS}=$ Mean Square

From the values gotten from the analysis on Table 4, the value of $\mathrm{R}^{2}$ is 0.7403 which means that $74 \%$ of the total variance in the impact of collaboration processes on success factors of a successful project has been explained. This implies that the data shows strong positive impact of collaboration processes between project actors on project success. This is in agreement with an assertion which stated that collaborative approach was responsible for the success of construction projects in terms of the completion to time and cost. [16]. Also, this finding corroborated the finding which states that collaboration among key stakeholders has positive impact on the success of construction projects [3].

Table 4. Regression Coefficients for Collaborative Processes and Project Success.

\begin{tabular}{|c|c|c|c|c|c|}
\hline & Multiple R & R square & Adjusted R square & Standard error & Sig. \\
\hline Impact & 0.860 & 0.740 & 0.708 & 1.069 & 0.740 \\
\hline
\end{tabular}

Note: Sig=Significance

\section{Conclusion}

Effective and efficient collaboration is proven to improve construction project so as to achieve success and this current study further established how the relationship between consultant and contractor influences project success in Nigeria. The study focused on contractors and consultants because they are the key stakeholder in construction. The finding from the results revealed that project actors are involved in all the collaborative processes though mostly involved in the process of clear roles and responsibility, information sharing, cooperation and coordination, improved communication and collaborative governance. Furthermore, the collaborative success factors of construction project are the efficient coordination, dedicated team and commitment to quality. Lastly, the collaborative processes among project actors have a positive impact on the success of construction projects. The study recommends that project actors should continually accept and practice all the levels and processes of collaboration during construction projects to pave way for implementing sustainability. All professional institutes/bodies involved in construction project collaboration should organize workshops, seminars, conference, etc. so as to enlighten professionals on the benefits of collaborating and to adopt digital collaboration.

The study is limited to the assessment of the interrelationship between contractor and consultant, further study should be undertaken to examine the collaboration among other project actors and team, and how their collaboration influences project success in other regions in Nigeria.

\section{References}

[1] Abdull-Rahman, S. H., Endut, I. R., Faisol, N. \& Paydar, S. (2014). The Importance of Collaboration in Construction Industry from Contractors' Perspectives. Procedia - Social and Behavioral Sciences, 129, 414-421.

[2] Afsarmanesh, H. \& Camarihna-Matos, L. M. (2008). Collaborative Networks: Reference Modeling. Proceedings of PROLAMAT'06 (Springer). Shanghai, China, 4-6 June, 2006.

[3] Ahmad, M., Saleh, M. \& Dash, A. (2018). Collaboration Impact on the Performance in Construction Projects: Case Study Selangor Malaysia. International Journal for Science and Advance Research in Technology, 4 (1), 11019-11028.

[4] Ahmed, A. (2019). Study Reveals New Impacts of Team Collaboration on Project Success. Available online at www.projectmangernews.com on November 16, 2019.

[5] Annett, S. \& Jervin, M (2014). Understanding the Difference between Cooperation and Collaboration. Retrieved online from http://leanconstructionblog.com on 4/6/2017.

[6] Arthur, T. H. (2007). Priniciples of Mutuality: Respect, Learning and Accountability. Available online at www.himmelmanConsulting.com On March 3, 2017. 
[7] Awodele. O. A. \& Ogunsemi, D. R (2010). An Assessment of Success Factors and Benefits of Project Partnering in Nigeria Construction Industry. Retrieved online from www.academia.edu on 4/6/2017.

[8] Batory, A. \& Svensson, S. (2019). The Fuzzy Concept of Collaborative Governance: A Systematic Review of the State of the Art. Central European Journal of Public Policy, 13 (2), 28-39. DOI: 10.2478/cejpp-2019-0008.

[9] Chen, B., \& Graddy, E. A. (2005). InterOrganizational Collaborations for Public Service Delivery: A Framework of Preconditions, Processes, and Perceived Outcomes. Paper presented at the 2005 ARNOVA Conference, November 1719, Washington, DC.

[10] Chen, W. T. \& Chen, T. T. (2007). Critical Success Factors for Partnering in Taiwan. International Journal of Project Management, 25 (5), 475-484.

[11] Child, S. \& Shaw, S. (2016). Collaboration in the $21^{\text {st }}$ Century: Implications for Assessment. Research Matters, 12, 17-22.

[12] Cristofoli, D., Meneguzzo, M. \& Riccucci, N. (2016). Collaborative Administration: The Management of Successful Network. Public Management Review, 19 (3), 275-283.

[13] De Saram, D. \& Ahmed, S. M. (2001). "Construction coordination activities: what is important and what consumes time." Journal of Management in Engineering, 17, 202-213.

[14] Emerson, K. K., Nabatchi, T. \& Balogh, S. (2012). An Integrative Framework for Collaborative Governance. Journal of Public Administration Research and Theory, 22 (1), 1-29.

[15] Eriksson, P. \& Westerberg, M., (2011). Effects of cooperative procurement procedures on construction project performance. Journal of Management in Engineering. 7, 211-218.

[16] Eriksson, P. E. \& Nilson, T., (2008). Client perceptions of barriers to partnering. Engeering, Construction and Architectural management, 527-539.

[17] Frey B. B., Jill, H. Lohmeier, Stephen W. Lee \& Nona Tollefson M (2006). Measuring Collaboration among Grant Partners. American Journal of Evaluation; 27; 383.

[18] Gadde, L. \& Dubois, A., (2010). Partnering in the construction industry - Problems and oppurtunitites. Journal of Purchasing \& Supply Management, 16, 254-263.

[19] Greer, P (2017). Elements of Effective Interorganizational Collaboration: A Mixed Methods Study. Unpublished Doctoral Thesis of the Leadership and Change Program, Antioch University.

[20] Ingirige, B. \& Sexton, M., (2006). Alliances in construction. Investigating initiatives and barriers for long-term collaboration. Engineering, Construction and Architectural Management, 13, 521-535.

[21] Jones, K. (2018). Improcing Collaboration in Construction. Available online at constructconnect.com on April 6, 2018.

[22] Lai E. R. (2011). Collaboration: A Literature Review. Retrieved online from www.pearsonassesment.com on 4/6/2017.
[23] Lofgren, P. (2009). Effect of Collaboration in Projects on Construction Project Performance. Unpublished Masters Thesis of the Department of Business Administration amd Social Sciences, Lulea University of Technology. www.divaportal.orgg on $25 / 7 / 2017$

[24] Magba, M., Cowden, R. \& Karodia, A. M. (2014). The Impact of Technological Changes on Project Management at a Company Operating in the Construction Industry. Arabian Journal of Business and Management Review (Nigeria Chapter), 2 (9), 113-148.

[25] McDonald, R. B. (2014). Collaboration Issues in between of disciplines in Construction Industry. Journal of Construction Procurement; 2 (1), 41-55.

[26] Murphey, T. \& Jacobs, G. M. (2000). Encouraging Critical Collaborative Autonomy. JALT Journal, 22, 220-244.

[27] Norberg-Johnson, D. (2015). What to expect: Collaboration on Construction Projects. Available online at www.ecmag.com on August 13, 2015.

[28] Olouasa, C. S. (2014). Mutuality and Partnership Effectiveness: A Case Study of a Triangular Cooperation Eduction Partnership. Masters Thesis Submitted to the Institute for Development Studies, University of Nairobi.

[29] Paisley, B (2015). Organizational learning in construction supply chains. Retrieved online from www.emeraldinsight.com on 3/6/2017.

[30] Pal, R., Wang, P. \& Liang, X. (2017). The Critical Factors in Managing Relationships in International Engineering, Procurement, and Construction (IEPC) Projects of Chinese Organizations. International Journal of Project Management, 1125-1237.

[31] Patel H. Pettitt, M \& Wilson, J. R. (2012). "Factors of collaborative working: A framework for a collaboration model." Applied Ergonomics, 43, 1-26.

[32] Sanders, D. and Costain, (2014). Collaborative Working relationships in Construction, Collaborative working \& procurement in construction. Retrieved from www.ciria.org/News/blog/Collaborative_working_relationship s on $23 / 8 / 2017$.

[33] Savolainen, P., Ahonen, J. J. \& Richardson, I. (2012). Software development project success and failure from the supplier's perspective: A systematic literature review. International Journal of Project Management, 30, 458-469.

[34] Thompson, (2016). The Essential Element of Effective Collaboration to Develop Sustainable Outreach and Enrollment Models. Retrieved online at coloradohealth.org on September 13, 2020.

[35] Thomson, A. M. (2001). Collaboration Processes: Inside the Black Box. Retrieved online from http://onlinelibrary.wiley.com on 4/8/2017.

[36] Westerveld, E. (2003). Project Excellence Model: linking success criteria and critical success factors. International Journal of Project Management, 21, 411-418. 